\title{
Synthetic progestogen-oestrogen therapy and uterine changes
}

\author{
J. G. AZZOPARDI AND I. ZAYID ${ }^{1}$ \\ From the Department of Morbid Anatomy, Royal Postgraduate Medical School of London
}

SYNOPSIS Continuous therapy with synthetic progestogen-oestrogen produces marked atrophy of endometrial glands and massive pseudodecidual stromal transformation. Cyclical therapy produces initially a 'frustrated secretory response' with precocious attempts at secretion in poorly developed glands. Pseudodecidua appears about the 20th day. With later cycles there is progressively greater gland atrophy while pseudodecidua is less marked. A possible inductive role of the glands on the stromal response to progestogens is postulated. The effect of different drugs and dosages is discussed.

Decidual necrosis may occur with heavy doses. The Arias-Stella reaction, previously regarded as diagnostic of pregnancy, can be produced with ordinary doses of these drugs. Suppression of spiral arterioles is usual. Ballooning of venules is a frequent finding, possibly accounting for breakthrough bleeding.

Red degeneration of myomata was present in three of seven hysterectomy specimens containing myomata.

The introduction of these drugs is important to the pathologist because they produce endometrial and other uterine changes with which one must be familiar for the interpretation of appearances in endometrial curettings and hysterectomy specimens. The synthetic progestational steroids can be divided into four groups on a chemical basis:-

\section{GROUP I : ALKYL DERIVATIVES OF TESTOSTERONE}

GROUP II: 19-NOR-TESTOSTERONE DERIVATIVES (a) Norethynodrel (present in Enavid and Conovid); (b) norethisterone (in orthonovum) and norethisterone acetate (in Anovlar and Gynovlar); (c) ethynodiol diacetate (in Metrulen); (d) lynestrol (in Lyndiol). These drugs are the most potent ovulation inhibitors and are also the drugs of choice in functional uterine bleeding. Many compounds have inherent oestrogenic activity or are metabolized to oestrogen.

GROUP III: $17 \alpha$-HYDROXYPROGESTERONE DERIVATIVES (a) Medroxyprogesterone acetate; (b) megestrol acetate; (c) chlormadinone acetate. These drugs are less

'Present address: Department of Pathology, Army Base Hospital, Amman, Jordan.

Received for publication 17 March 1967. powerful ovulation-inhibitors than group II drugs. They have no inherent oestrogenic activity and do not metabolize to oestrogen.

GROUP IV: PROGESTERONE DERIVATIVES

Drugs of groups II and III are used as contraceptives, in the treatment of endometriosis and of functional uterine bleeding. Most proprietary preparations contain oestrogen combined with a synthetic progestogen. Some, like Primolut N, contain progestogen only.

\section{MATERIAL}

Material from 44 patients was originally studied. In two patients histories were unreliable; one patient had an unsuspected endometritis and one was possibly pregnant. Material from the remaining 40 patients constitutes the basis of this study. Seven patients had continuous therapy, 18 had cyclic therapy as a contraceptive (17 of these had a normal menstrual history), while 15 had cyclic therapy for menstrual disorders, usually menorrhagia or metrorrhagia. Hysterectomy specimens were examined in 12 patients, endometrial curettings in 28. 


\section{RESULTS}

CONTINUOUS THERAPY Of seven patients on continuous therapy, one was in the recovery phase. The remaining six were treated for periods varying between one and six months. One had proven endometriosis, five had heavy or irregular periods. Five of the six patients showed similar responses; four were given combined treatment; one had Primolut $\mathrm{N}$ alone. Dose varied between $10 \mathrm{mg}$. Conovid and $30 \mathrm{mg}$. Enavid daily. The interval between the last drug administration and operation was only one day. The glands are mostly small, inactive and devoid of mitoses (Figs. 1-3). A few glands show slight secretory activity in a patient treated for 40 days with $10 \mathrm{mg}$. Conovid daily. The stroma comprises the bulk of the endometrium and shows striking changes. There is marked pseudodecidual change with conversion of most stromal cells into large, bloated, polygonal cells (Table I); this change affects the superficial stroma more markedly than the deeper part (Figs. 1, 3). Moderate to marked oedema is present. Pseudopolymorphs (körnchenzellen) are present in varying numbers (Fig. 2). There is no unusual concentration of mononuclear cells. Occasional plasma cells in one case are probably related to an endocervicitis. The pseudodecidua may be as striking as the decidua of early pregnancy but the discrepancy between glandular and stromal appearances clearly distinguishes the iatrogenic changes from early pregnancy decidua. Striking vascular changes are present with suppression of spiral arterioles and development of numerous thin-walled vessels. In two of the five patients, irregular uterine bleeding persisted up to the time of hysterectomy or curettage and yet florid pseudodecidua was found.

In two cases portions of frankly necrotic decidua are present. Pregnancy could be ruled out because of atrophic glands and other findings. One patient had had a tubal sterilization 10 years previously. These patients received $15 \mathrm{mg}$. Primolut $\mathrm{N}$ daily for six months and 20 to $30 \mathrm{mg}$. Enavid daily for four weeks respectively.
One of the six specimens did not show the characteristic picture. Cystic endometrial hyperplasia was found before treatment. Primolut $\mathrm{N}$ was given for six weeks. The last menstrual period was three weeks before hysterectomy. Microscopy shows a midsecretory endometrium without dissociation between glandular and stromal changes. Interpretation is reserved until later.

CYCLIC THERAPY Thirty-three patients were treated from day 5 to day 25 of the menstrual cycle. Combined treatment with progestogen and oestrogen was used. Ten patients were in the recovery phase. Of the remaining 23, 13 were normal women treated for fertility control and 10 were on treatment for irregular or heavy bleeding. All patients were treated with 19nor-testosterone derivatives.

It is difficult to generalize about the effect of cyclic therapy because differences are found, depending on drug dosage, the number of cycles of therapy, and other factors. The following applies to patients taking 5 to $10 \mathrm{mg}$. norethynodrel or 3 to 5 or even $10 \mathrm{mg}$. norethisterone acetate.

In the first few cycles glandular proliferation, gauged by size and mitoses, is diminished and then abolished. Subnuclear vacuolation occurs early and is prominent at about nine to 12 days; supranuclear vacuoles may also be found. Subnuclear vacuoles are present in rather small glands, usually distinguishable from the larger more tortuous glands of a normal 17th day endometrium (Fig. 4). As epithelial vacuolation recedes, luminal secretion appears about the 12th day, reaches a peak about the 14th or 15th day and disappears slowly thereafter. Secretion is scanty and on cursory examination the glands may appear nonsecretory. The glands become smaller later in the cycle (Figs. 5 and 6) but a few tortuous glands may remain. Stromal proliferation is also suppressed but pseudodecidual change usually takes place about the 20th day of the cycle, i.e., after 15 days of treatment, becoming progressively more pronounced and sometimes as conspicuous as that of the normal menstrual

TABLE I

\begin{tabular}{|c|c|c|c|c|c|c|c|}
\hline & \multirow{3}{*}{$\begin{array}{l}\text { SUMMARY OF } \\
\text { No. of } \\
\text { Cases }\end{array}$} & \multicolumn{2}{|c|}{ MAIN FINDINGS IN 29 PATIENTS } & \multicolumn{2}{|c|}{ ON TREATMENT } & & \\
\hline & & \multirow{2}{*}{$\begin{array}{l}\text { Glands } \\
\text { Mostly } \\
\text { Atrophic }\end{array}$} & \multirow{2}{*}{$\begin{array}{l}\text { Well Developed } \\
\text { Secretory Glands }\end{array}$} & \multirow{2}{*}{$\begin{array}{l}\text { Vacuolation } \\
\text { in Atrophic } \\
\text { Glands }\end{array}$} & \multicolumn{3}{|c|}{ Pseudodecidua } \\
\hline & & & & & Slight & Moderate & Marked \\
\hline Continuous therapy & 6 & 5 & $1^{1}$ & $\mathbf{0}$ & $\mathbf{0}$ & 1 & 4 \\
\hline \multicolumn{8}{|l|}{ Cyclical therapy } \\
\hline A Short term (1 to 5 cycles) & 11 & 8 of $9^{2}$ & $\begin{array}{l}1 \text { of } 9(+1 \text { focal } \\
\text { included in previous } \\
\text { coiumn) }\end{array}$ & 3 of 8 & 2 & 3 & 3 \\
\hline B Long term (6 or more cycles) & 12 & 12 & 0 & 1 & 3 & 1 & $\mathbf{0}$ \\
\hline
\end{tabular}

${ }^{1}$ For explanation of exceptional cases in this column see text.

'Two patients with metrorrhagia and glandular epithelial changes unlike anything seen in gynaecologically normal women on these drugs are excluded from the table except for the stromal changes. 


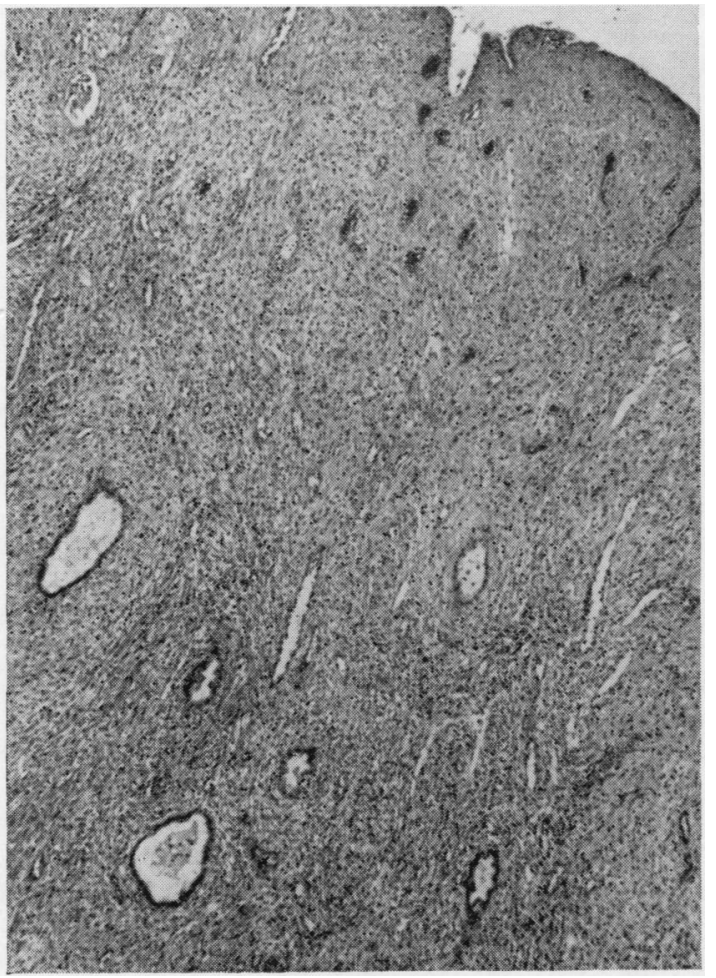

FIG. 1. Forty days' continuous therapy with Conovid $10 \mathrm{mg} . /$ day. Gland atrophy, pseudodecidua in superficial endometrium, dilated vessels. Haemalum and eosin $\times 38$.

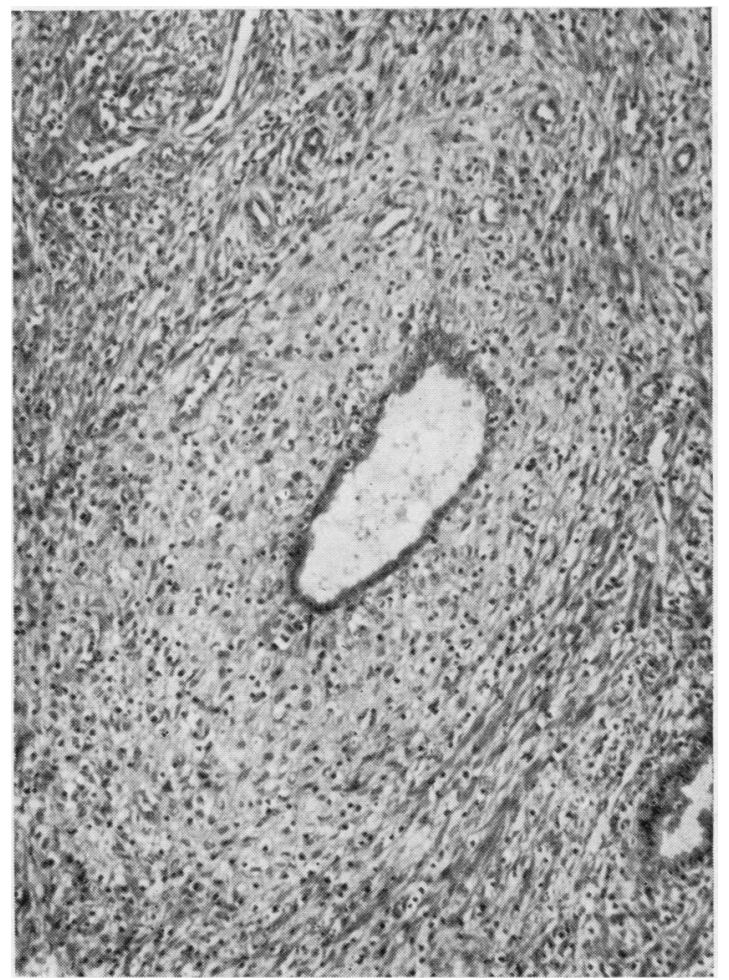

FIG. 2. Same case as in Figure 1. Periglandular halo of pseudodecidua. The small dark cells are pseudopolymorphs. Haemalum and eosin $\times 100$.

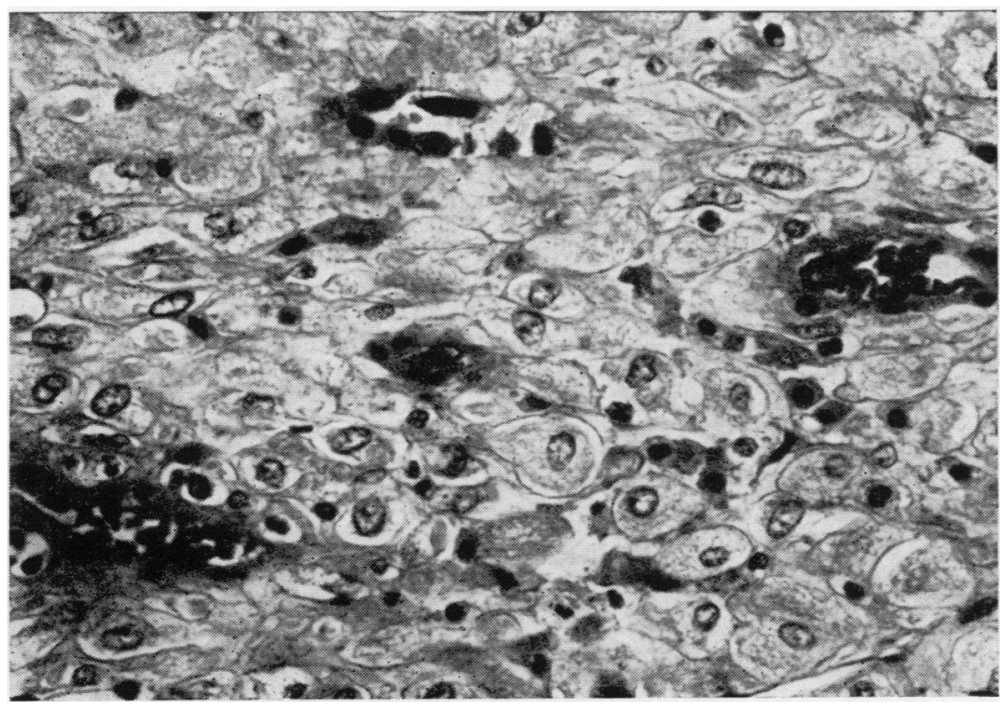

FIG. 3. Five months' continuous therapy with Enavid $10 \mathrm{mg}$./day. Gross pseudodecidual response with solitary atrophic gland at the top. Haemalum and eosin $\times 400$. 


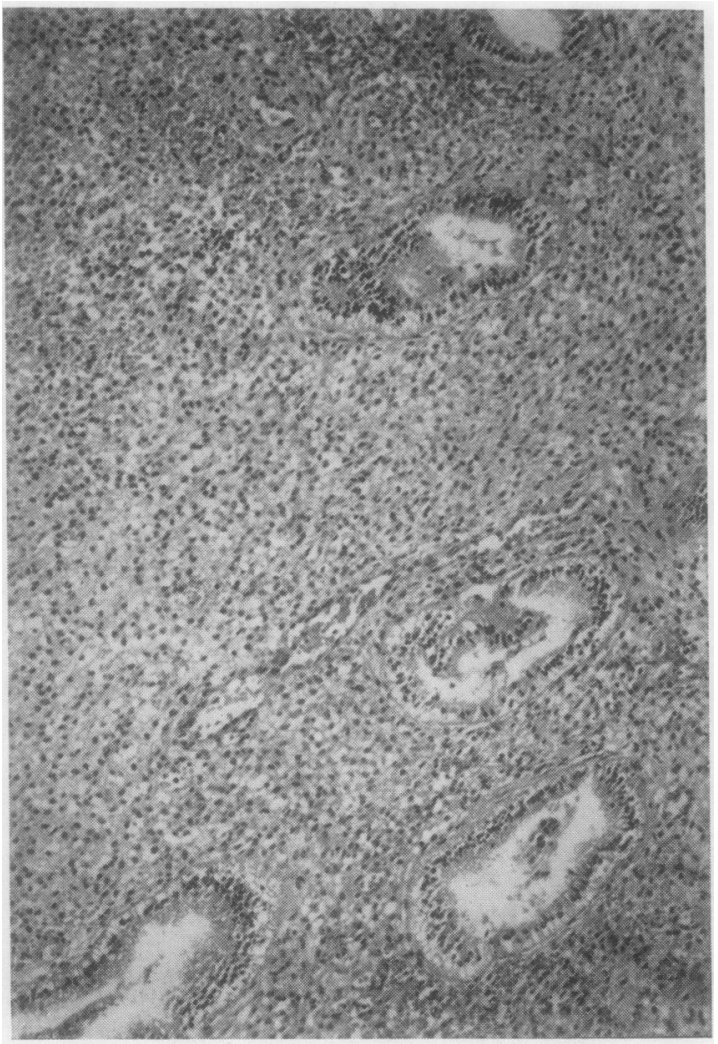

FIG. 4. Ten months' cyclical Conovid E $2.5 \mathrm{mg} . /$ day. Twelfth cyclical day. Subnuclear vacuolation in straight glands. The glands are considerably smaller on a 5 or $10 \mathrm{mg}$. daily dose. Haemalum and eosin $\times 100$.

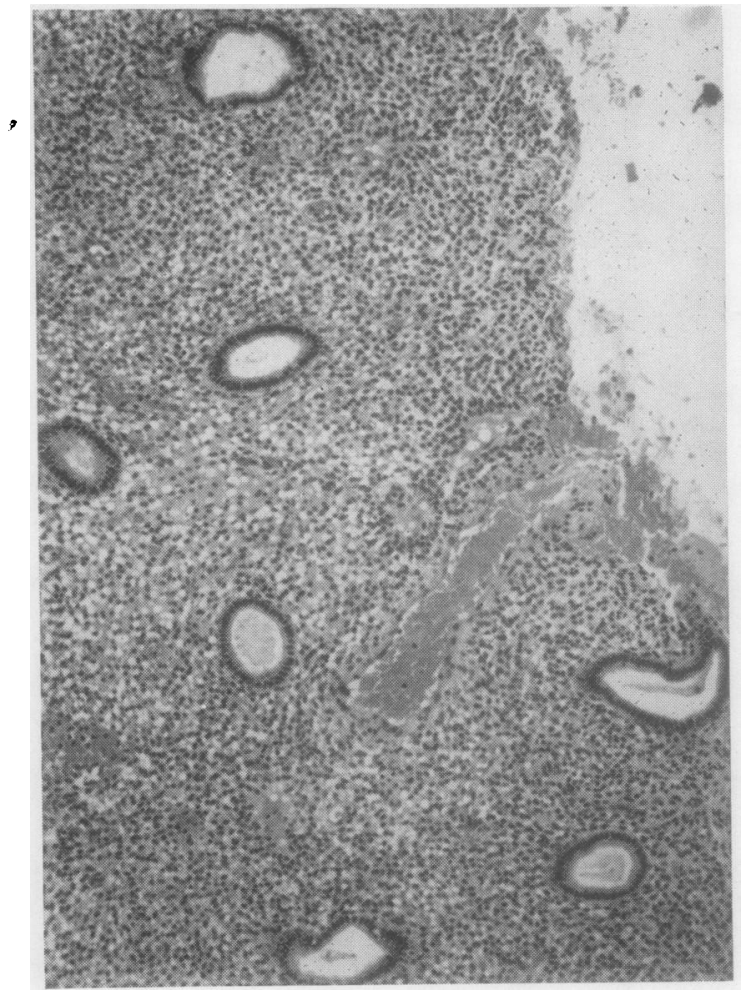

FIG. 5. Three months' cyclical Orthonovum $2 \mathrm{mg}$./day. Twenty-third cyclical day. Small inactive glands. A little periglandular and perivascular pseudodecidua in other fields. Haemalum and eosin $\times 100$.

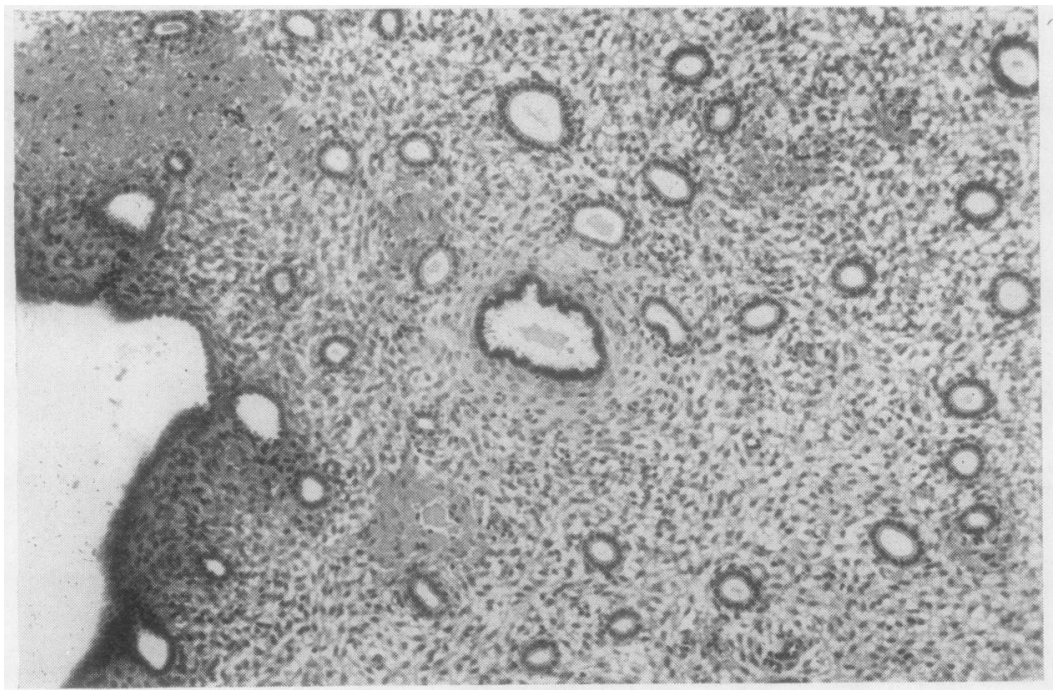

FIG. 6. Four month' cyclical Gynovlar $3 \mathrm{mg}$./day. Nineteenth cyclical day. Severe gland atrophy with periglandular pseudodecidua around a larger gland. Haemalum and eosin $\times 100$. 


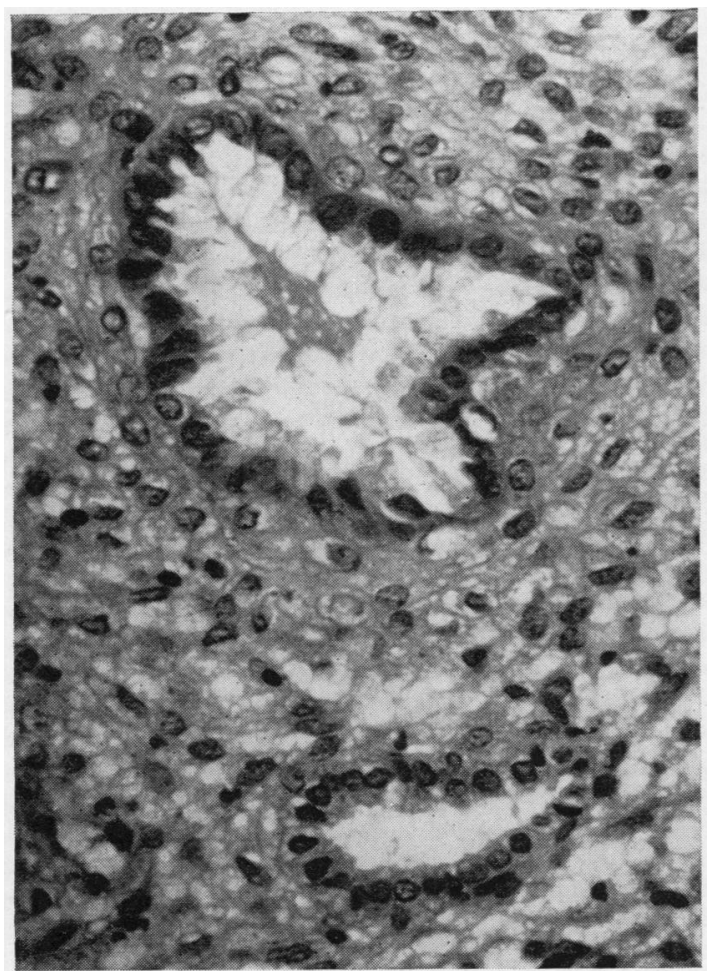

FIG. 7. Same case as in Figure 6. Arias-Stella-like reaction in upper gland. Haemalum and eosin $\times 400$.

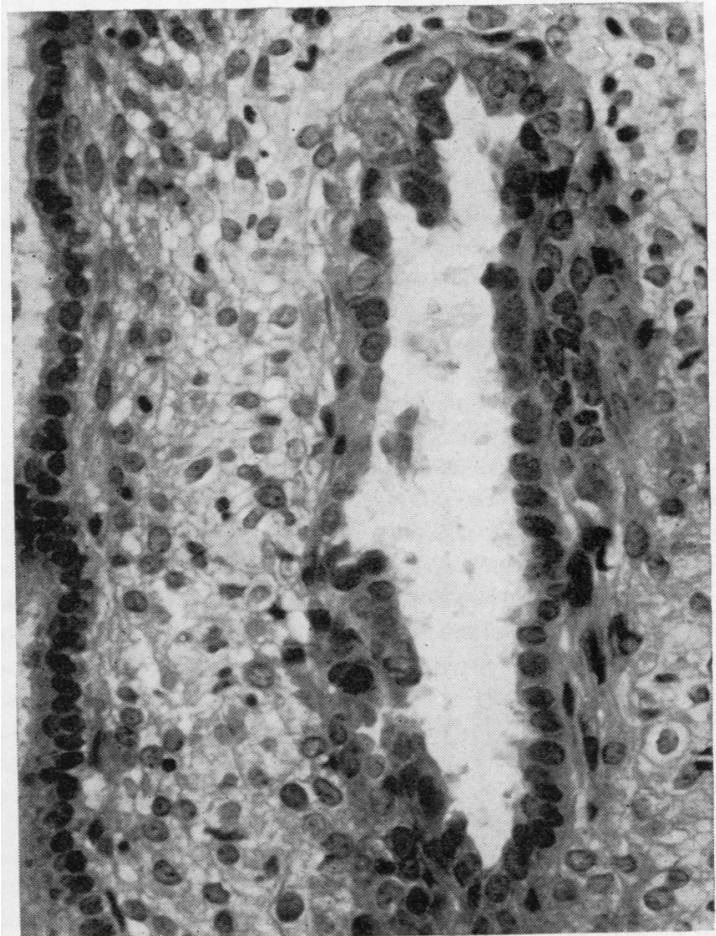

FIG. 8. Same case as in Figure 7. Arias-Stella-like reaction with nuclear anisochromasia, epithelial tufting, loss of polarity, etc. Haemalum and eosin $\times 400$.

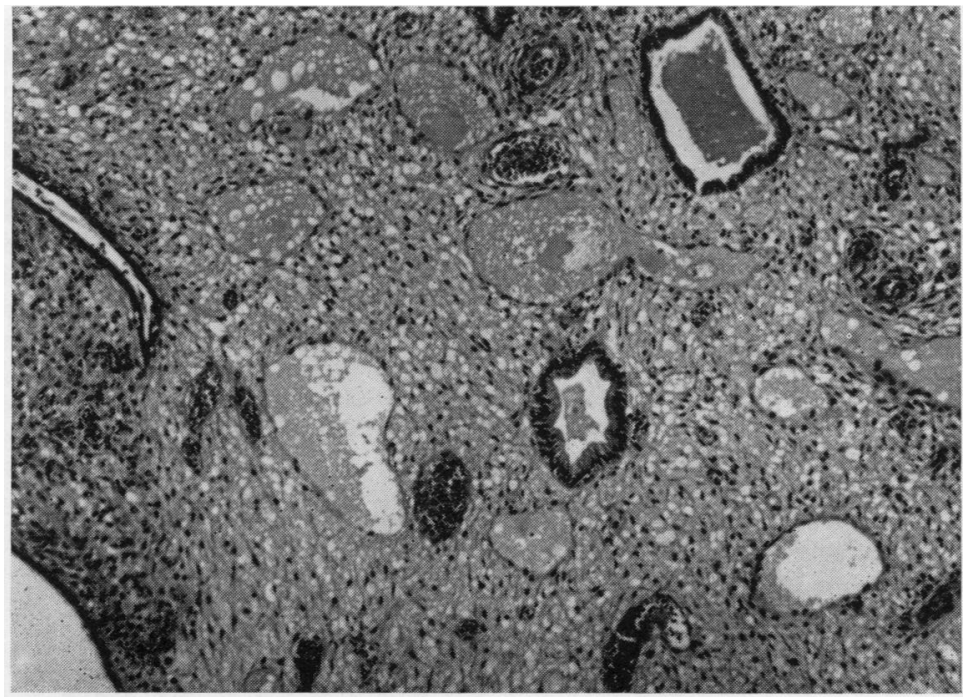

FIG. 9. Cyclical Enavid 10 to $20 \mathrm{mg} . /$ day for 12 days. Moderate gland atrophy, gross stromal oedema and ballooning of superficial vessels. Other areas show pseudodecidua. Haemalum and eosin $\times 100$. 
cycle (Table I). Pseudodecidua, often more marked in the superficial endometrium, shows also a tendency to localize around glands and vessels (Fig. 6). A variable degree of stromal oedema is found at any time of the cycle. With the second to fifth cycles glands tend to remain progressively smaller, attaining a lesser degree of development early in the cycle. Pseudodecidua is less marked; by the fourth or fifth cycle it may be very patchy and inconspicuous. From the sixth to the 60th cycles endometrial glands are usually uniformly small, with inactive epithelium virtually devoid of mitoses, with dense eosinophilic cytoplasm and a sharp luminal edge. Luminal secretion is now minimal or absent but subnuclear vacuolation may still be seen, especially with small doses (Fig. 4). The stroma is mostly dense and inactive, individual cells have little cytoplasm, the overall appearance resembling the stroma of postmenopausal endometrium. Stromal mitoses are rarely found. The endometrium is very thin, possibly accounting for the reduced withdrawal bleeding that patients may experience. Pseudodecidua may be altogether absent or, if present, takes the form of very small superficial patches, or haloes around glands.

Two of the 23 cases contain foci of decidual necrosis. They were treated with larger doses than are used for contraception, one receiving 5 to $10 \mathrm{mg}$. Enavid initially and $20 \mathrm{mg}$. for the five days before curettage, the other receiving $20 \mathrm{mg}$. Enavid daily for eight days.

Glandular changes indistinguishable from the Arias-Stella reaction are present in two of the 13 gynaecologically normal women taking drugs as a contraceptive. Only some glands show Arias-Stella change; these are rather larger than the majority of the glands which are small and tubular (Figs. 7 and 8 ). The epithelium in affected glands varies between columnar with sharp luminal edges and cells with bulbous luminal margins; the nuclei are relatively large, variable in size and staining intensity, and sometimes situated in the bulbous portion. In both cases small foci of periglandular pseudodecidua are present; these periglandular haloes are strikingly associated with the slightly larger glands showing Arias-Stella change.

Vascular changes are similar to those seen on continuous therapy. There is partial or complete suppression of development of spiral arterioles, with development of thin-walled sinusoids which sometimes appear ectatic (Fig. 9). These sinusoids can be mistaken for dilated glands with flattened epithelium. In one patient with Arias-Stella change, an endometrial polyp contains large branched glands and an abundance of muscular arterioles, i.e. looks very different from the remainder of the endometrium.

Two patients with abnormal gynaecological histories merit separate mention. In one, curettage for met- rorrhagia showed cystic endometrial hyperplasia. Following Primolut $\mathrm{N}$ for two cycles, curettage revealed secretory glands and a pseudodecidual re- -7 action. Curettage in a second patient with metrorrhagia showed focal hyperplasia. After one cycle of Enavid therapy, curettage on the 26th day showed a few secretory glands among a majority of small nonsecretory ones.

RECOVERY PHASE This covers curettings from patients who have discontinued treatment for seven days or $\omega_{\sigma}$ more, except for one patient with a gap of only four days. Eleven patients were in the recovery phase, one after continuous therapy for four months, 10 after 0 cyclical therapy for periods varying between two and 0 . 48 months. In the patient on continuous treatment curettage revealed, four days after stopping therapy, $\circ$ an early proliferative endometrium with epithelial, $\stackrel{ }{\triangle}$ but very rare stromal, mitoses. This appears to indi- $\vec{\rho}$ cate that partial recovery can take place in only four $\mathbb{D}$ days. In the 10 patients on cyclical therapy, treatment $\mathbb{D}$ had been discontinued for between four months and $\bar{g}$ only seven days. Curettage showed normal prolifera- $\stackrel{\mathbb{\Phi}}{\rightarrow}$ tive or secretory endometrium in all. As examples of $\vec{\theta}$ the endometrial capacity to recover, two instances are cited. A patient on $2.5 \mathrm{mg}$. Conovid $\mathrm{E}$ for four years as a contraceptive and another treated for almost one year with massive Enavid therapy of up to $80 \mathrm{mg}$. daily for uncontrollable metrorrhagia both had normal proliferative endometria after stopping treatment. While no abnormalities were seen in these 11 patients, in a patient still on continuous therapy a small,circum- $\overline{\bar{a}}$ scribed stromal nodule of fibroblast-like cells is present.

MYOMETRIUM Of 12 cases undergoing hysterectomy, seven had uterine myomata and, of these, three showed red degeneration. These patients received 3 treatment for periods of nine days, four weeks, and six weeks respectively. The first received only $1 \mathrm{mg}$. Metrulen $M$ daily for nine days; the last was on continuous therapy for six weeks with Primolut N. In all three cases multiple myomata were present but $\frac{D}{0}$ only one in each case showed red degeneration. In two this affected the largest myoma present $(9 \mathrm{~cm}$. and $N$ $4 \mathrm{~cm}$.) while in the third, one of the smaller myomata $\mathrm{N}$ $(1 \mathrm{~cm}$.) was affected.

\section{DISCUSSION}

CONTINUOUS THERAPY This produces florid pseudo- $\mathbb{\Phi}$ decidual change but with dissociation between gland- + ular and stromal effects. Dockerty, Smith, and $\frac{0}{0}$ Symmonds (1959) drew attention to this change in $\underset{\mathbb{D}}{ }$ their case 3. The development of abnormal thin- $\frac{?}{\mathbb{D}}$ walled vessels in these endometria is probably respons- $\varrho$ 
ible for the breakthrough bleeding that may occur. In two of our cases uterine bleeding persisted up to the time of hysterectomy or curettage and yet the endometrium was still thick and showed pseudodecidua. This we believe represents bleeding without menstruation.

Since continuous therapy is used in the treatment of endometriosis, it is noteworthy that ectopic endometrium may respond like the normally placed tissue (Lebherz and Fobes, 1961). This can lead to the pathologist being confronted with a biopsied or resected 'tumour' with very baffling appearances.

CYCLICAL THERAPY Depressed gland proliferation and 'frustrated secretion' epitomize the epithelial changes. Epithelial vacuoles appear precociously but the secretory response is incomplete and luminal secretion diminished. Repressed secretion is probably the result of and proportionate to failure of glandular development. Pseudodecidua appears about the 20th day and may become well developed. With subsequent cycles epithelial vacuolation is slighter, perhaps because gland atrophy is more complete, and pseudodecidual change is less marked. The finding of slight pseudodecidua as early as the seventh day by Ryan, Craig, and Reid (1964) was not confirmed. This variation with the number of cycles was seen also by Rice-Wray, Aranda-Rosell, Maqueo, and Goldzieher, (1963). The reason for the lessening of the pseudodecidual response is far from clear though one possibility is that development of endometrial glands plays an inductive role in the response of the stroma to progestogen. This is suggested by a few cases with pseudodecidua around larger glands when there is none around completely atrophic ones. An alternative possibility is that alterations in vascular flow account for the diminished stromal response.

EFFECT OF SIZE OF DOSE Flowers (1964) found no variation between successive cycles using low-dosage therapy. Epithelial vacuolation appeared somewhat later, while there was no pseudodecidual change. Subnuclear vacuolation was consistently present in the second year of therapy, perhaps because this lowdosage therapy caused less gland suppression early in the cycle (Fig. 4)! In this context it is believed that progestogen allows endometrial glands to secrete by antagonizing oestrogen, which is a secretion inhibitor (Ober, 1966). At the other end of the scale, treatment with, say, $20 \mathrm{mg}$. norethynodrel for eight to 10 days can produce pseudodecidua seen oply after 15 to 20 days of more moderate dosage. Within limits, a larger dose produces earlier change or more intense widespread effect; there is a partial exception in the case of secretory change which may be actually less prominent with the larger dose, where the latter has effected severe gland atrophy.

EFFECT OF TYPE OF DRUG The effects produced by drugs of groups II and III are similar but with quantitative differences. Ethynodiol diacetate in the 1 to 2 $\mathrm{mg}$. dose usually prescribed causes little or no pseudodecidual reaction. The $17 \alpha$-hydroxyprogesterone derivatives produce less intense pseudodecidua than the 19-nor-testosterone derivatives (Ober, 1966). In addition to group differences, there are minor differences between individual drugs. Maqueo, Perez-Vega, Goldzieher, Martinez-Manautou, and Rudel (1963) found that norethynodrel, compared with norethisterone, caused more oedema (Fig. 9), earlier and more marked gland regression, and less pseudodecidual reaction: conversely, with norethisterone, secretory changes were more marked and pseudodecidua better developed. These differences are relatively minor.

Decidual necrosis, Arias-Stella-like changes and vascular changes warrant individual mention.

DECIDUAL NECROSIS This was noted in four of the 29 cases. It may make one suspect pregnancy, as happened in one of our cases, until it became clear that drugs alone can cause this. High dosage appears to be necessary for this effect; duration of therapy is not important. No necrosis was seen in patients on more moderate dosage as used for contraceptive purposes.

ARIAS-STELLA-LIKE CHANGES These changes were present in two women taking moderate drug doses as contraceptive therapy. It has hitherto been accepted that the Arias-Stella reaction only occurs in the presence of trophoblastic tissue and that it is a sign of pregnancy in uterine and extrauterine sites (Birch and Collins, 1961; Mackles, Wolfe, and Pozner, 1961). However, Arias-Stella (1955) found that this reaction could be induced by giving oestrogen and progesterone for 18 to 20 days to castrated rats; oestrogen alone failed to produce this effect.

VASCULAR ALTERATIONS Ober drew attention to the importance of vascular changes. Inhibition of development of spiral arterioles is common to all progestogen-oestrogen regimens. Dilated venules are often present, more frequently in therapy with 19nor-testosterone than with $17 \alpha$-hydroxyprogesterone derivatives. With less than $2 \mathrm{mg}$. of any type of drug venule ectasia is rare.

EFFECT ON ABNORMAL ENDOMETRIA Treatment converted two previously hyperplastic endometria into near-normal secretory endometria while a third case of focal endometrial hyperplasia showed, after treatment, focal secretory glands among atrophic ones. It 
is tempting to think that the 'overprimed' endometrium responds by the development of secretory glands. Should further data confirm this, it would imply that the presence after treatment of full-blown secretory glands probably indicates a preceding hyperplasia.

RECOVERY PHASE Discontinuation of therapy is believed to lead to a return to a normal endometrium and this is true of our 11 cases. Charles (1964), however, reported abnormalities in three patients after stopping treatment, viz., squamous metaplasia in endometrial glands, an endometrial myoma, and a fibrous stromal nodule; a minute stromal nodule similar to the latter was present in one of our cases on therapy. It is important to document all such changes to establish any relationship to therapy.

MYOMETRIUM Dockerty et al. reported myometrial vascular congestion and red degeneration of uterine myomata in a postmenopausal woman. No fewer than three of our seven cases with myomata showed this change. It can occur with a small dose, after a brief period of therapy, and with progestogen alone.

Myometrial hypertrophy and congestion, red degeneration of myomata, florid pseudodecidual change, and an Arias-Stella reaction are the anatomical component of an induced pregnancy-like state which has biochemical, haematological, and clinical equivalents. The changes produced by synthetic progestogenoestrogen therapy mimic those of pregnancy, with the difference that there is no foetus.

We are grateful to Professor J. McClure Browne and his department for free access to their clinical data. We wish to thank Professors C. V. Harrison and J. Browne, and Dr. K. Fotherby for valuable discussion, Miss J. Allen for help with the pharmaceutical nomenclature, and Mr. B. Chalk and Mrs. V. Chalk for technical and secretarial assistance.

\section{REFERENCES}

Arias-Stella, J. (1955). Arch. Path., 60, 49.

Birch, H. W., and Collins, C. G. (1961). Amer. J. Obstet. Gynec., 81, 1198

Charles D. (1964). J. clin. Path., 17, 205.

Dockerty, M. B., Smith, R. A., and Symmonds, R. E. (1959). Proc. Mayo Clin., 34, 321.

Flowers, C. E., Jr. (1964). J. Amer. med. Ass., 188, 1115.

Lebherz, T. B., and Fobes, C. D. (1961). Amer. J. Obstet. Gynec., 81, 102.

Mackles, A., Wolfe, S. A., and Pozner, S. N. (1961). Ibid., 81, 1209.

Maqueo, M., Perez-Vega, E., Goldzieher, J. W., Martinez-Manautou, J., and Rudel, H. (1963). Ibid., 85, 427.

Ober, W. B. (1966). J. clin. Path., 19, 138.

Rice-Wray, E. Aranda-Rosell, A. Maqueo, M., and Goldzieher, J. W. (1963). Amer. J. Obstet. Gynec., 87, 429.

Ryan, G. M., Jr., Craig, J., and Reid, D. E. (1964). Ibid., 90, 715. 